\title{
Revista
}

(Ropp) Gestão \& Políticas Públicas

n² 2 - 22 Semestre 2011

Artigo Especial

Reforma gerencial do Estado, teoria política e ensino da administração pública

Luiz Carlos Bresser-Pereira ${ }^{1}$

${ }^{1}$ Fundação Getúlio Vargas.

Ministro da Fazenda (1987).

Ministro da Administração Federal e Reforma do Estado (1995-1998).

Ministro da Ciência e Tecnologia (1999).

Correspondência: bresserpereira@gmail.com.br

www.bresserpereira.org.br 


\section{Reforma gerencial do Estado, teoria política e ensino da administração pública}

A Reforma Gerencial do Estado de 1995 ficará como um marco do esforço de reconstrução do Estado brasileiro, como uma mudança decisiva para viabilizá-lo como um Estado Social voltado para a garantia dos direitos sociais dos cidadãos, e para habilitá-lo a competir em um mundo global em que os estados nacionais se tornaram mais estratégicos do que antes, embora tenham se tornado também mais interdependentes.

Esse tipo de reforma está acontecendo em quase todos os países desenvolvidos. Entre os países em desenvolvimento, o Brasil está na dianteira, embora haja também algum avanço no Chile. A reforma iniciada há 16 anos atrás ganhou o coração e as mentes dos altos administradores públicos e dos professores e alunos das escolas de administração pública e de políticas públicas. Nesta breve nota farei um breve resumo da reforma para, em seguida, discutir o problema do ensino da administração pública. Argumentarei então que esse ensino está mais próximo da ciência política e particularmente da teoria do Estado do que da administração de empresas.

A reforma gerencial do Estado deve ser compreendida no âmbito de duas grandes forças que moldaram a sociedade contemporânea no século XX. De um lado, a globalização, o fato de o capitalismo haver-se tornado dominante em nível mundial, e os mercados terem sido todos abertos para a competição capitalista. Isto obrigou os países a serem mais competitivos, e, por isso, contarem com um Estado que além de mais legítimo, porque democrático, fosse mais eficiente porque gerencial.

De outro lado, a democracia social, o fato de que na segunda metade do século XX, principalmente na Europa, o Estado passou a garantir também os direitos sociais. Para isso criou grandes serviços sociais e científicos de educação, saúde, pesquisa, previdência e assistência social, que exigiram que a administração pública fosse mais do que simplesmente efetiva, fosse também eficiente, ou, em outras palavras, que fosse mais do que uma administração pública burocrática: fosse uma administração pública gerencial.

A reforma burocrática ocorreu na Europa no século XIX foi a primeira grande reforma administrativa do Estado moderno. Ela se desenrolou no quadro de um pequeno Estado liberal que se limitava a garantir os direitos civis ou as liberdades individuais, que deixara de ser absoluto, passara a garantir os direitos civis, mas continuava essencialmente autoritário porque negava aos pobres o direito universal ao voto.

A reforma burocrática, conforme assinalou Max Weber em sua grande análise da burocracia, tornou o serviço público profissional e a dominação, racional-legal. 
Esse Estado representava menos de $10 \%$ da renda nacional dos países, e, por isso, precisava apenas ser efetivo.

Mas na primeira metade do século XX o Estado nos países desenvolvidos se tornou democrático (na medida em que passou a assegurar o sufrágio universal), e, na segunda metade desse século, além de democrático torna-se social. A primeira mudança mudava o regime político, o sistema constitucional-legal, a segunda exigia uma mudança da administração pública ou do aparelho do Estado.

No Estado social, a despesa pública passou a representar mais de $40 \%$ da produção nacional. Tornava-se, assim, necessário que o Estado se tornasse além de efetivo, eficiente. Que acompanhasse o aumento da produtividade que ocorre no setor privado para que haja desenvolvimento econômico.

A reforma gerencial - a segunda grande reforma administrativa do Estado moderno - começou nos anos 1980 na Europa. A reforma foi uma resposta àquelas duas grandes forças que definiram o século XX - a globalização e a democracia social - uma resposta que a administração pública burocrática não lograva dar porque foi produto de um Estado Liberal.

No Brasil, a Reforma Gerencial de 1995 foi - e continua a ser, já que está em pleno processo de implementação - uma resposta aos desafios apresentados pela transformação do Estado brasileiro em um Estado social, depois da transição democrática de 1985. Talvez o primeiro Estado social entre os países em desenvolvimento.

A transição democrática que ocorreu no Brasil foi fruto de um grande pacto político democrático e popular. Nesse grande acordo informal formaram-se dois consensos: que o Estado deveria voltar a garantir os direitos políticos e se tornar democrático, e que esse Estado deveria promover uma melhor distribuição de renda porque a sociedade brasileira era uma sociedade injusta, marcada por excessiva desigualdade.

Entretanto esse compromisso político que foi assumido então não significava que se deveriam estabelecer impostos progressivos, mas aumentar a despesa social do Estado. Quando, em 1988, a nova Constituição brasileira garantiu o direito universal à saúde, estava cumprindo esse acordo.

Para tornar o Estado brasileiro um Estado social era preciso aumentar substancialmente a despesa pública social. E isto foi feito. Em 1985 ela representava cerca de $11 \%$ da renda nacional, hoje representa $23 \%$. Quando, no Ministério da Administração Federal e Reforma do Estado, eu dei início a Reforma Gerencial do Estado de 1995, eu estava respondendo a essa nova realidade que era o Estado social brasileiro. 


\section{Administração pública e as empresas}

Essa introdução deixa muito claro que o estudo da administração pública está inserido no estudo mais amplo do Estado. E, portanto, que a administração pública enquanto disciplina faz parte da ciência e da teoria política e não de uma prática, a prática da administração ou da gestão.

A aproximação que ocorreu no Brasil entre administração de empresas e administração pública decorreu de uma noção equivocada do que é a administração pública. E levou muitas universidades a oferecer cursos de administração com especialização em administração de empresas ou em administração pública, ao invés de aproximar a administração pública da ciência politica.

Como a administração de empresas é o processo de tomar decisões relativas aos objetivos das empresas ou das organizações privadas, como é a forma de planejar, organizar e controlar as ações em empresas, como é a maneira pela qual seu pessoal deve ser escolhido, treinado e motivado, supôs-se que a administração pública fosse a mesma coisa aplicada ao Estado, ou, mais amplamente, às organizações públicas e a seus serviços científicos, culturais e sociais. Podemos pensar a administração pública nestes termos - em termos de maneira de administrar - mas nesse caso seria melhor dizer "gestão" ao invés de “administração" pública.

Administração pública propriamente dita é outra coisa, é um dos dois elementos que constituem um Estado, o outro sendo a lei. O Estado-nação é a unidadepolítico territorial própria do capitalismo constituída por uma nação, um território, e um Estado. Este, por sua vez, é o sistema constitucional-legal e a administração pública ou organização ou aparelho de Estado que define e garante esse sistema constitucional-legal.

O Estado, portanto, é constituído, de um lado, pela lei e pelas políticas públicas, e, de outro, pela administração pública - esta entendida como organização pública soberana. Uma organização formada e dirigida por oficiais públicos eleitos e não-eleitos, ou, em outras palavras, por políticos, servidores públicos e militares, cabendo aos primeiros a definição da lei e das políticas públicas e aos segundos, participar dessa formulação de políticas e executá-las.

Além de uma organização pública soberana, a administração pública é uma disciplina que se ensina nas universidades. Seu objeto é o aparelho do Estado, e, portanto, está mais próxima da teoria política (cujo objeto é o Estado como um todo), ou do direito (cujo objeto é a lei), do que da administração de empresas.

Naturalmente como é preciso administrar as organizações privadas, é preciso administrar o aparelho do estado, geri-lo de forma eficiente. E isto se torna especialmente importante quando o Estado se torna um Estado Social e assume a execução de grandes serviços sociais e científicos. Mas o essencial na 
administração pública, aquilo que a distingue radicalmente das organizações privadas, é sua soberania, é seu poder de Estado, é a capacidade dos políticos de definir boas leis e políticas públicas, e a capacidade dos servidores de executálas.

Um curso de graduação ou de pós-graduação em administração pública não se limita a formar servidores; forma também, de um lado, políticos, e, de outro, administradores das organizações públicas não-estatais, principalmente das de advocacia ou de responsabilização política através das quais a sociedade civil busca responsabilizar a administração pública.

Podemos pensar no servidor ou burocrata público como um mero executor das decisões tomadas pelos políticos em nome de seus eleitores. Mas essa é uma visão linear e equivocada do que é um servidor público. O servidor público não é um mero gestor; ele é, essencialmente, um agente político como o é também o político eleito; por isso ambos são "oficiais públicos".

O servidor público não se limita a executar leis e políticas; ele ajuda os políticos eleitos a formulá-las ou a reformá-las. Seu poder não é apenas o poder de um administrador sobre seus subordinados. Ele fala e age em nome do Estado, ele partilha do poder de Estado, do poder extroverso e soberano que só o Estado tem sobre sua sociedade nacional.

Para formar administradores públicos não basta ensinar-lhes estratégias de gestão como a administração por resultados, métodos de controle, e uma visão geral da economia e da sociedade, de como evoluem e como são coordenadas.

Além disso, de que também a administração de empresas necessita, o administrador público precisa ter uma compreensão ampla da instituição normativa e organizacional que realiza essa coordenação, ou seja, do Estado; precisa saber quais são as teorias que buscam explicá-lo e relacioná-lo com a sociedade; precisa saber o que é o cidadão e quais são seus direitos, e o que é a democracia: a forma por excelência que assume o Estado moderno e desenvolvido; deve ter noções de direito constitucional e de direito administrativo; deve entender como o Estado se financia, e como controla os recursos que recebe da sociedade.

Na formação de administradores públicos - de um grupo restrito e altamente qualificado de agentes públicos dotados de poderes e responsabilidades públicas - é preciso também incluir a ampla discussão do que seja o etos público do servidor. Uma escola de administração pública ou de políticas públicas não pode se limitar a ensinar os valores liberais baseados na liberdade negativa de cada cidadão de não ser incomodado se não estiver infringindo a lei.

Ou, pior ainda, não pode ser limitar a ensinar a teoria neoliberal da "escolha pública" segundo a qual os oficiais públicos são bandidos que apenas fazem compensações entre a vontade de ser reeleito ou de ser promovido e a busca de rendas. O debate sobre a liberdade positiva ou sobre a concepção republicana de 
política e de serviço público é fundamental em um curso em administração pública, seja ele de graduação ou de pós-graduação. É fundamental por uma questão de dever ser, e, também, por uma questão de ser: porque a maioria dos servidores públicos sabe de suas responsabilidades para com a sociedade e o Estado.

Poder-se-ia argumentar que todo curso universitário deveria incluir essa preocupação. Sem dúvida, já que todas as profissões supõem comportamento ético e implica uma ética própria a ela. No caso dos oficiais públicos eleitos e não-eleitos, porém, o etos republicano está no próprio coração dessas profissões.

A sociedade exige das demais profissões a ética que lhe é própria; dos políticos e do administrador público ela exige a responsabilidade pela res publica, exige o compromisso com o interesse público. A responsabilidade pela construção de um Estado democrático e republicano é de todos os cidadãos, mas é principalmente de seus oficiais públicos.

Em uma sociedade democrática os burocratas ou oficiais públicos desempenham um papel estratégico. Eles governam essa sociedade. Eles tomam ou ajudam a tomar as grandes decisões sobre as leis ou as instituições do país, ou sobre questões específicas referentes a relações nacionais e internacionais. Eles afetam de forma duradoura a vida dos cidadãos. Por isso é preciso que os servidores públicos constituam parte da elite intelectual do país. Que sejam poucos, bem remunerados, e escolhidos entre os jovens mais talentosos desse país.

Não faz sentido, principalmente no nível federal e estadual, que o Estado continue fazendo concursos públicos para carreiras que não exigem diploma superior. Porque só faz sentido para o Estado dar status de servidor público aos servidores de carreira de Estado - a oficiais públicos que exerçam poder de Estado.

Enquanto as funções menores exercidas dentro do aparelho do Estado devem ser terceirizadas para empresas, as funções nobres de educação, saúde, cultura, assistência e previdência social devem ser transferidas para entidades públicas não-estatais - as organizações sociais.

Aos oficiais públicos cabe definir as políticas pelas quais as organizações se pautarão, definir com elas os contratos de gestão, e em seguida controlá-las. Estas são funções nobres e específicas do Estado, envolvem poder de Estado, e por isso devem ser exercidas por pessoas capazes, devidamente formadas em cursos que os insiram na sociedade em que vivem e no Estado que administram, e que os façam compreender tanto essa sociedade quanto esse Estado.

Uma sociedade só será desenvolvida e democrática se contar com um Estado capaz ou forte. E para isso é preciso que, além da legitimidade de suas leis e de seus governantes, ele conte com a competência de seus oficiais públicos. 